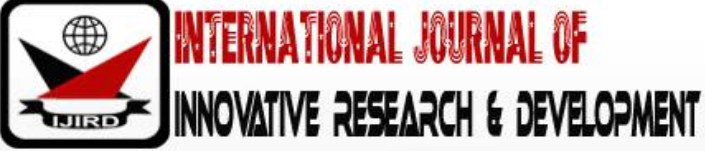

ISSN 2278 - 0211 (Online)

\section{The Attitudes of the Jordanian EFL Teachers toward Employing the Phonological Awareness Skills in Teaching English as a Foreign Language}

\begin{tabular}{c}
\hline Samer Radwan Hmeadat \\
Ph.D. Student, University Sultan Zainal Abidin, Malaysia \\
Kamariah Yunus \\
Professor, University Sultan Zainal Abidin, Malaysia \\
\hline
\end{tabular}

\begin{abstract}
:
No one denies the importance of being phonologically aware. A large body of research confirmed the key role of phonological awareness to enhance students' abilities to able to decode automatically and accurately. However, this study was conducted to investigate the Jordanian EFL teachers' attitudes toward integrating their EFL classrooms the main levels of phonological awareness and that was considered the question of the study. Practically, and in order to answer the question study, a qualitative research method through a research tool was employed. Therefore, a wellprepared questionnaire was run. The reliability and validity of the questionnaire were both taken into consideration. The sample study consisted of (200) participants distributed in different municipalities in the Hashemite Kingdom of Jordan, especially in Zarqa municipality. The findings of the study were not satisfactory and revealed dearth in competence among teachers, besides, most of EFL teachers detracted from the importance of phonological awareness to create a generation of students who are able to read rapidly and accurately. The results also showed clear gap in phonological awareness among the EFL teachers in the practical side. Consequently, the researcher recommended other researchers to shed light more on the teachers' capacities and their awareness to practically employ phonological awareness and its subtasks; segmentation, blending manipulation and other phonological types explicitly. Besides, the researcher recommended also EFL teachers to keep up to date revolutionary researches related to instruction methods.
\end{abstract}

Keywords: Phonological awareness, EFL teachers, target language, educational reforms

\section{Introduction}

Phonological awareness is considered crucial and plays a significant role in teaching English especially during the preschool stage and primary stages. Plethora and a large body of studies confirmed the key role of phonological awareness to enable children to be independent decoders and fluent readers in a later stage (Yopp, 2010; Oleimat, 2018;Westerveld and Barton, 2017; Roux et al, 2016; Al Shaboul, 2016; Oleimat, 2016; Neumann, Marbach, Grande, Willmes, and Heim , 2015; Carrada, 2015; Eisa,2014; Eissa, 2013 and Calderaro, 2013). Besides, it represents a positive start to promote young learners reading and develop the essential tools to help them decode words automatically, rapidly and accurately (Gillon, 2012; Al Tamimi and Rabab'ah, 2007). According to (McBride, 2015; Yopp, 2010) the tasks of phonological awareness are necessary tools for literacy development and improving reading skills and they are considered as an urgent foundation. These tasks have its positive effect even on those children who have learning difficulties in learning to read. However, these tasks should be employed and assessed by qualified and trained teachers in order to get high gains. Accordingly, phonemic awareness is considered the most complicated and crucial of phonological awareness (Gillon, 2017; Gillon, 2012; Yopp, 2010; Schuele and Boudreau, 2008; Al Tamimi and Rabab'ah, 2007).

In Jordan, different educational reforms took place during the last decade to improve teaching English. Some described the situation as a crisis of education (Abu Nab'ah, Al Omari, Ihmeideh and Wa'lly,2009). At the time, English as a foreign language was taught at the early beginning from grade five until grade twelve (AL-Jarrah and Talafhah, 2015). Since 1990s, different reforms were held by patronage of his majesty King Abdullah II Bin Al Hussein and Queen Rania. Other reforms were held in 2001, 2002 and later on the ministry of education launched the conference known as 'Education Reform for the knowledge Economy Project (ERfKE) from 2003 to 2009 as the first phase, and from 2009-2015, the second phase. (SABER Country Report, 2015). As a result, responding and acting on the royal directives, the ministry of education would spare no effort to develop curriculums and make English in specific as an obligatory school subject starting from the first grade in order to fit from all the reforms held and to come up with the increasing demands of the sufficient processes of learning and teaching and to create a positive environment for learning English effectively (Alhabahba, Pandian and Mahfoodh, 2016). As a consequence, one of the recommendations of these educational reforms was the improving the image of the target qualified teacher. Therefore, EFL teachers must have a robust satisfactory grasp 
of the essential skills that foster and promote early reading success and demonstrate an understanding of their responsibilities related to the nature of their job in order to be aware of what they do. (Alkhawaldeh, 2017.; Kabadayi, 2016).

\subsection{Problem Statement}

Many different studies were conducted to investigate the impact of phonological awareness on reading and writing performance and all of them stressed the importance of equipping children with the essential phonological awareness tools to be self-taught decoders and later on to be fluent readers. But few, if any, local studies discussed the EFL teachers' attitudes toward integrate this vital factor as phonological awareness in our daily models of teaching here in Jordan.

\subsection{Research Question}

What are the EFL teachers' attitudes toward teaching phonological awareness in Jordan?

\subsection{Research Purpose}

The study aims to investigate the EFL teachers' attitudes toward empowering children phonologically and investigate their attitudes toward the ability of teachers to create a new generation of those students who are phonologically aware. It also sheds light on phonological teachers' capacities and qualifications to be ready to deal with this important issue.

\subsection{The Significance of the Study}

Eventually, phonological awareness instruction as an approach of teaching proved its effectiveness among children and even among low levels of students who were ret aught through this approach. Therefore, the researcher wants to highlight and review the EFL teachers' attitudes toward integrating and employing phonological awareness skill in the classroom activities and investigate EFL teachers' readiness to equip their students with the essential tools they need to be phonologically aware and to reach together a satisfactory stage for all sides; students, parents (guardians) and teachers.

\subsection{Limitations of the Study}

However, the study was confined to a sample of EFL teachers in Jordan. Besides, teachers' ages ranged in between 24-55 years old. The academic year was 2019/ 2020.

\section{Literature Review}

Phonological awareness is the conscious and explicit knowledge that words are composed of individual segments. Besides, it is the conscious awareness that a sentence (as a large unite) is made up of smaller units (words) and that words can be divided into onsets and rimes (Porta, Carrada and Ison, 2015; Downing,2013; Ong, 2014; Myers,2014; Grawburg and Rvachew, 2007). According to many researchers and experts in the field, phonological awareness is an indicator and a precursor to reading difficulties (Alshaboul, 2016; Oleimat, 2016; Eisa, 2014). In other words, those who had low levels of phonological awareness, they have become definitely poor readers in their next grades (Baddeley and Gathercole, 2014; Gillon, 2012).

This section involves two parts, the first one discusses the teacher's situation and the second part represents the studies that tackle the role of phonological awareness as a main predictor of fluent readers.

\subsection{Studies of EFL teachers in Jordan}

The study of Al Bataineh (2019) worked to clarify English learning thoughts among EFL students in Jordan, and worked also to investigate whether female and male students were different in their beliefs regarding teaching and learning English. As research method, the study used a survey instrument to investigate EFL participants' thoughts about language learning relating to gender. The study consisted of (83) students divided into (35 males) and (48 females), and their ages ranged between 18 to 45 years old. The study was limited to participants of English language at a private university. However, the findings of the study showed that males and females were not significantly different with respect to English language communication strategies employed, the nature of language learning, and language aptitude, as well. The study recommended that the results could also help instructors of English to develop better language learning atmosphere and teaching-learning processes.

The study of Yassin (2015) confirmed that the current methods of teaching were not sufficient and satisfactory for children. The study which consisted of (five) ESL instructors and (30) ESL participants confirmed that some of the teaching methods employed in some of the classrooms in Jordan were not contemporary. This study which used qualitative research methods was conducted to determine the obstacles that encounter students and hinder them from learning and prevent teachers from teaching effectively in their classrooms. Accordingly, the researcher claimed that lack professionalism and teaching commitment were one of the challenges that face both teachers and students. And, it asserted that some of the EFL teachers claimed that it was very difficult to employ new and effective teaching strategies. Besides, it was undoubtedly clear, according to them, that difficulty could be explained because students were not ready for these new methods and the insistence to use the mother tongue language frequently was another factor, as well.

The study of Al-Jamal (2007) also investigated the learning and teaching experiences of English pupils and teachers in AlKarak District in Jordan. The subjects of the study were one hundred and twenty-six (126) high school students and 
twenty-six (26) teachers. Respectively, the research tools of the study were two prepared questionnaires and purposefully interviews in order to check and investigate the subjects' attitudes toward the instruction they received. The findings of the study showed high levels of weakness among students regarding learning English and they preferred using the target language (English) more than the mother tongue (Arabic) in the classroom. The results of the study revealed to what extent teaching models employed were conventional and unfruitful. As a consequence, students were passive doers and were frustrated from the whole situation. The recommendation of the study was that methods of instruction strategies should have been introduced and included in English language teaching employing new approaches that might help students improve their learning levels.

\subsection{Phonological Awareness}

According to the report of the National Early Literacy Panel (2008), there are 'six variables' which represent a strong predictor and an index to early literacy skills and these variables are highly linked with strong positive later literacy and prepare future fluent readers. These six variables are: First, Alphabet knowledge or the cognition of both (names and sounds) and the correspondences between them. Second, Phonological awareness, or the capacity to consciously understand that larger units can be divided into smaller and smaller units. Third, Rapid Automatic Naming of letters, which means the ability to name letters quickly and automatically. Fourth, Rapid Automatic Naming of objects and colours. Fifth, Writing and the sixth one is the phonological memory, which meant the ability to remember and recite spoken information for a while. Hence, the researcher chose one of these six variables to build this study up.

However, phonological awareness is the ability to mentally work with individual speech sound (manipulation) (Westervelt and Barton, 2017; Łyda and Szcześniak, 2014; Yopp, 2011). It is a broad concept that involves the metalinguistic understanding and the conscious perception of the segments structure of language (Goldsworthy and Pieretti, 2013; Gillon, 2012; Yopp, 2010; Torgesen and Mathes, 2002; Birch, 2000). Similarly, phonological awareness means the sensitivity of spoken sounds and the ability to manipulate these sounds within words away from meaning. In addition, the focus of phonological awareness lies on the oral language but not on the print form or (graphemes) and here the distinction between phonics and phonological awareness emerges. In phonics, students deal with written forms, symbols or letters that represent the sound (Gillon, 2017; Gillon, 2012; Eissa, 2014; Yopp, 2010). According to Goswami and Bryant,2016; Cassuto, Sartori and Giolfo,2016) phonological awareness has separate units but they are interrelated and depend on each other, these units are: phoneme awareness or phonemic awareness (grapheme-phoneme correspondences and alliteration, blending and segmenting distinct phonemes), word awareness (onset-rime), rhyming( simply noticing the ending sounds of a set of words) and sentence segmentation awareness.

Phonemic awareness is considered a part of the big umbrella 'phonological awareness'. It means the ability to recognize sounds of a word then to be able to analyze and manipulate these sounds by addition, deletion, alteration, blending and segmenting (westerveld and Barton,2017; Eissa ,2014; Łyda and Szcześniak,2014; Schuele and Boudreau, 2008). It tackles smaller units in specific, meanwhile, phonological awareness deals with larger units such as words, syllables and sentences. (Gillon, 2017; Gillon,2012; Myers,2014; Yopp,2011; Sawyer and Fox 1991).

\subsection{Related Studies}

The study of Baezzat, Moradi and Motaghedifard (2018) discussed the effect of training phonological awareness skills on the improvement of auditory memory in students with spelling problems in the third grade at primary schools in Sari City, Iran. A quasi-experiment with pre-tests, post-tests, and a control group were employed to investigate the effect of the program. The participants who were purposefully selected through three diagnostic tests were (20) students. Then, these students were randomly assigned to two groups; the experimental group that was taught through the training program and the control group which was taught normally using the conventional method.

The results of the study revealed that there was a clear significantly difference between the experimental group and the control group indicating that phonological awareness intervention improved the auditory memory of participants who had spelling problems. Further, the study indicated that the awareness of sounds enables children to read and write words well because they recognized the association between letters and sounds.

The study of Cárnio, Vosgrau and Soares (2017) was conducted to investigate the performance of 4th gradeElementary School participants with and without signs of reading and writing disorders as for phonological awareness. The participants of the study consisted of (60) students from two public schools. For data collection, the Chi-Square test, the Kruskal-Wallis test and the Spearman correlation coefficient were all employed. All the subjects were individually tested regarding their phonological awareness and reading comprehension of sentences. As a consequence, the findings of the study showed that students with no signs of reading and writing disorders had a higher performance in the tasks tested. In addition, the results also showed the pre-correlations between the phonological awareness and the text and sentence reading comprehension revealed the key role of meta-phonological tasks.

The study of Alshaboul (2016) aimed at exploring the extent of the readiness of pre-service EFL teachers to teach English reading in their thoughts, knowledge, and awareness of PA. A modified questionnaire was administered to a sample of subjects $(\mathrm{N}=158)$. Results of the study revealed that the dominance of the conventional teaching thoughts, defect in competence, dearth in teaching models, and a clear gap in PA awareness. Moreover, the study showed that efforts should be geared towards fostering teachers' awareness and perceptions of the significant learners' awareness in shaping their capacities to read and decode the print. Further, kindergarten children should have many opportunities to be involved in certain practices that educate them about rhyme, onsets, rimes, initial sounds, and syllables. 


\section{Methodology}

\subsection{Sample of the Study}

The population of this study consisted of all the EFL teachers in Az Zarqa 1st Directorate of Education, Az Zarqa. The sample consisted of (200) male and female participants who were selected randomly in order to investigate their attitudes toward employing phonological awareness tasks in teaching English as a foreign language in primary, elementary and secondary stages in order to equip children with the key tools to be able to decode words and become fluent readers in later on stages.

\subsection{Tools of the Study}

The researcher administered a qualitative research through using a well-prepared questionnaire to find out and investigate the attitudes of EFL teachers distributed in different places in Jordan toward the use of phonological awareness as an explicit and conscious teaching approach. Validation and reliability of the questionnaire were all taking into consideration. The data collected was analyzed through SPSS. Besides, a pilot study was run.

\subsubsection{A Questionnaire}

For validity purposes, the questionnaire was geared to a group of EFL teachers in widespread different schools inside the First and Second Directorate of Education in Zarqa and other school outside the municipality. A pilot test of the questionnaire was conducted on (20) EFL teachers (outside of the sample) to test the reliability of the current questionnaire. The questionnaire involved three parts; the first one consisted of (11) general statements about the topic, the second part included (9) little deeper level statements and the last one involved (24) direct viable multiple-choice questions to gauge teachers' phonological awareness levels in order to assess teachers' own PA knowledge. See appendix (1). A Cronbach Alpha reliability coefficient of has been reported indicating a high level of reliability of the scale for the first part of the questionnaire as follows;

\begin{tabular}{|c|c|c|}
\hline \multicolumn{3}{|c|}{ Reliability Statistics Part One } \\
\hline Cronbach's Alpha & Cronbach's Alpha Based on Standardized Items & N of Items \\
\hline .821 & .724 & 11 \\
\hline
\end{tabular}

Table 1

Besides, the Cronbach Alpha reliability coefficient of the second part was recorded as follows;

\begin{tabular}{|c|c|c|}
\hline \multicolumn{3}{|c|}{ Reliability Statistics Part Two } \\
\hline Cronbach's Alpha & Cronbach's Alpha Based on Standardized Items & N of Items \\
\hline .909 & .913 & 9 \\
\hline
\end{tabular}

Table 2

Further, a Cronbach Alpha reliability coefficient has been reported indicating a high level of reliability of the scale for the third part of the questionnaire as follows;

\begin{tabular}{|c|c|c|}
\hline \multicolumn{3}{|c|}{ Reliability Statistics Part Two } \\
\hline Cronbach's Alpha & Cronbach's Alpha Based on Standardized Items & N of Items \\
\hline .831 & .839 & 24 \\
\hline
\end{tabular}

Table 3

The validity was also administered through consulting a panel of university professors and educational experts in the field. All panel's recommendations and suggestions were taken seriously and their notes were modified by addition or deletion.

\section{Results and Discussion}

The questionnaire included three parts. The first two parts included general background knowledge about phonological awareness from a side and English teaching principles based on that awareness. Meanwhile, the third one encompassed a deeper level of phonemic awareness grasp. The table below illustrates percentages of the subjects participated in the survey.

\begin{tabular}{|c|c|}
\hline Item & Percentage \\
\hline Male teachers & $53.3 \%$ \\
\hline Female teachers & $46.7 \%$ \\
\hline \multicolumn{2}{|c|}{ Level of Education } \\
\hline BA & $86.7 \%$ \\
\hline MA & $13.3 \%$ \\
\hline
\end{tabular}

Table 4: Shows Percentages of the Participated Target Sample 
However, the first part of the questionnaire addressed the general background of the subjects. This part shed the light on English teachers' attitudes and their perspectives about essential issues related phonological awareness and their linguistic competence. However, the results were somehow shocking and impressive.

\begin{tabular}{|c|c|c|c|c|c|c|c|c|c|c|c|}
\hline & Item 1 & Item 2 & Item 3 & Item 4 & Item 5 & Item 6 & Item 7 & Item 8 & Item 9 & Item 10 & Item 11 \\
\hline Disagree & $14.5 \%$ & $\mathbf{0 . 0} \%$ & $10.5 \%$ & $\mathbf{0 . 5} \%$ & $4.5 \%$ & $6.5 \%$ & $7.5 \%$ & $3.5 \%$ & $15.5 \%$ & $9.5 \%$ & $9.5 \%$ \\
\hline Strongly disagree & $13.0 \%$ & $17.0 \%$ & $7.0 \%$ & $40.5 \%$ & $18.5 \%$ & $10.0 \%$ & $6.5 \%$ & $9.0 \%$ & $\mathbf{4 7 . 5 \%}$ & $16.0 \%$ & $39.5 \%$ \\
\hline Agree & $12.5 \%$ & $29.0 \%$ & $27.0 \%$ & $18.5 \%$ & $31.5 \%$ & $25.5 \%$ & $30.5 \%$ & $30.5 \%$ & $12.5 \%$ & $30.0 \%$ & $15.0 \%$ \\
\hline Strongly Agree & $13.5 \%$ & $17.5 \%$ & $31.0 \%$ & $9.5 \%$ & $10.5 \%$ & $21.5 \%$ & $38.5 \%$ & $22.0 \%$ & $11.5 \%$ & $15.0 \%$ & $11.5 \%$ \\
\hline No Idea & $\mathbf{4 6 . 5 \%}$ & $36.5 \%$ & $24.5 \%$ & $31.0 \%$ & $35.0 \%$ & $36.5 \%$ & $17.0 \%$ & $35.0 \%$ & $13.0 \%$ & $29.5 \%$ & $24.5 \%$ \\
\hline Total & $100 \%$ & $100 \%$ & $100 \%$ & $100 \%$ & $100 \%$ & $100 \%$ & $100 \%$ & $100 \%$ & $100 \%$ & $100 \%$ & $100 \%$ \\
\hline Mean & 3.65 & 3.74 & 3.52 & 3.30 & 3.53 & 3.72 & 3.51 & 3.76 & 2.59 & 3.39 & 3.02 \\
\hline Std. Deviation & 1.52 & 1.13 & 1.23 & 1.30 & 1.26 & 1.24 & 1.08 & 1.13 & 1.25 & 1.31 & 1.37 \\
\hline & \multicolumn{7}{|c|}{ Green is the lowest } \\
\hline
\end{tabular}

Table 5: Shows Likert Scale Survey Percentages of Each Item

The given table shows the percentage of the teachers' responses for the (11) items of the first part of the questionnaire. As observed, the highest point recorded was for the item that talked about 'Syllables, rimes and onsets should be taught in the primary stage'. Eventually, $47.5 \%$ of the subjects' responses strongly disagreed about that. In contrast, $11.5 \%$ only strongly agreed. This percent confirmed that EFL teachers were not well-educated about phonological awareness. It can be noticed that $13 \%$ of the participants had no idea about it. Interestingly, this item scored the less mean among the other items to record only (2.59). Meanwhile, the other item that deserved attention was item 4 , titled "Poor PA (awareness of the individual sounds in words) contributes to early reading failure', $0.5 \%$ of the subjects disagreed. This percentage also indicated that EFL teachers were unconvinced about the key role of phonological awareness. Similarly, the other item titled 'PA does not take care of the written language' indicated that $0 \%$ disagreed on. Thus, this item recorded the highest mean (3.74). However, the first item titled 'Phonological Awareness is a topic which I studied at the university' recorded the highest percentage (46.5\%) for favor those who had no idea whether they studied phonological awareness at university or not.

However, looking at percentages of the item number (11) which was titled 'I spend more than 10 minutes in teaching phonemic awareness gave us a close outlook about the real situation in the EFL classroom. Thus, (11.5\%) responded strongly agreed. Meanwhile, (39.5\%) strongly disagreed indicating that they even knew nothing to be given or taught to their students. In like manner, the item number (8), that titled Teaching the rime and onset is not important for the first graders. The responses were also shocking. $35 \%$ of the responses had no idea about whether rime-onset is important or not. In contrast, only $22 \%$ strongly disagreed.

\begin{tabular}{|c|c|c|c|}
\hline Mean & Variance & Std. Deviation & N of Items \\
\hline 37.72 & 26.83 & 5.18 & 11 \\
\hline
\end{tabular}

Table 6: Shows Scale Statistics of the First Part of the Questionnaire

The second part of the questionnaire involved little deeper statements about phonological awareness. Table (4) shows the percentages of each item.

\begin{tabular}{|c|c|c|c|c|c|c|c|c|c|}
\hline & Item 1 & Item 2 & Item 3 & Item 4 & Item 5 & Item 6 & Item 7 & Item 8 & Item 9 \\
\hline No & $38.5 \%$ & $42.0 \%$ & $31.0 \%$ & $31.5 \%$ & $31.5 \%$ & $15.5 \%$ & $47.5 \%$ & $46.5 \%$ & $38.5 \%$ \\
\hline Yes & $16.5 \%$ & $18.0 \%$ & $29.0 \%$ & $24.0 \%$ & $47.0 \%$ & $51.0 \%$ & $26.5 \%$ & $21.0 \%$ & $29.5 \%$ \\
\hline No Idea & $45.0 \%$ & $40.0 \%$ & $40.0 \%$ & $44.0 \%$ & $21.5 \%$ & $33.5 \%$ & $26.0 \%$ & $32.5 \%$ & $32.0 \%$ \\
\hline Total & $100 \%$ & $100 \%$ & $100 \%$ & $100 \%$ & $100 \%$ & $100 \%$ & $100 \%$ & $100 \%$ & $100 \%$ \\
\hline Mean & 2.07 & 1.98 & 1.97 & 2.06 & 1.90 & 2.18 & 1.79 & 1.86 & 1.94 \\
\hline Std. Deviation & .914 & .908 & .868 & .866 & .723 & .678 & .832 & .880 & .839 \\
\hline
\end{tabular}

Green is the lowest Yellow is the highest

Table 7: shows Percentages of Part Two

It can be noticed that item number (6) titled 'I think that PA is a complicated issue that should not be presented to first graders' scored the highest percentage (51\%). As a consequence, most of the participants confirmed that phonological awareness should not be taught during the first grade. In contrast, only (15.5) stress that it should be. However, the lowest 
percentage was scored for the favor of item (1) which was titled 'I know well what Phonological Awareness is'. (16.5\%) responded 'yes' about their recognition of phonological awareness. Similarly, (45\%) responded to item number (1) that they had no idea about what phonological awareness is, which leaves no doubt that a lot of EFL teachers in Jordan were not well-educated and well-informed about phonological awareness. Table (5) shows the scale statistics of part two of the survey.

Besides, the responses to item number (9) titled 'I appreciate the importance of PA manipulation skills' were interesting. 32\% responses had no idea about the key role of manipulation skills of phonological awareness. Equally important, 38\% responses were (NO). Similarly, the responses to item (3) titled T know how to teach each level in the right way' were also impressive. $40 \%$ were totally ignorant about how to teach phonological awareness. Whereas, only $29 \%$ knew how to teach it and integrate in the English curriculum according to claims. Hence, only $24 \%$ confirmed they could assess the tasks of phonological awareness given to students. That was obvious according to their responses to item number (4), titled 'I know how to assess each level of phonological awareness'. Meanwhile, 44\% stressed that they had no idea about how to phonologically assess tasks.

\begin{tabular}{|c|c|c|c|}
\hline Mean & Variance & Std. Deviation & N of Items \\
\hline 17.74 & 32.91 & 5.74 & 9 \\
\hline
\end{tabular}

Table 8: shows the Scale Statistics of Part Two of the Survey

The third part of the questionnaire involved (24) direct practical multiple-choice questions related to phonological awareness. These questions represented EFL teachers' deeper understanding to the topic in order to assess teachers' own knowledge of phonological awareness. Table (6) illustrates the percentages of each item showing the highest and lowest answers for each item.

\begin{tabular}{|c|c|c|c|c|c|c|c|c|c|c|c|c|c|}
\hline & Item 1 & Item 2 & Item 3 & Item 4 & Item 5 & Item 6 & Item 7 & Item 8 & Item 9 & Item 10 & Item 11 & Item 12 & Item 13 \\
\hline highest Score & $35 \% a$ & $41.5 \% b$ & $32 \% b$ & $28 \% a$ & $41 \% \mathrm{~b}$ & $3.5 \% \mathrm{e}$ & $29.5 \% a$ & $35 \% \mathrm{e}$ & $38 \%$ & $39.5 \% a$ & $38 \% a$ & $26.5 \% \mathrm{c}$ & $48.5 \% a$ \\
\hline the lowest score & $8 \% d$ & $11.5 \% \mathrm{~d}$ & $2 \% d$ & $6.5 \% \mathrm{~d}$ & $6 \% d$ & $6.5 \% \mathrm{~d}$ & $5.5 \% d$ & $5 \% d$ & $5.5 \% d$ & $16.5 \% \mathrm{~d}$ & $3.5 \% \mathrm{c}$ & $12.5 \% \mathrm{~d}$ & $10.5 \% d$ \\
\hline Number of right answers & $11 \% \mathrm{C}$ & $41 \% B$ & $24 \% C$ & $25.5 \% \mathrm{C}$ & $6 \% \mathrm{D}$ & $23 \% B$ & $23 \% B$ & $5 \% \mathrm{D}$ & $5.5 \% \mathrm{D}$ & $21 \% B$ & $13 \% \mathrm{D}$ & $26.5 \% \mathrm{C}$ & $48.5 \% A$ \\
\hline Mean & 2.7 & 2.7 & 2.9 & 2.6 & 3.1 & 3.0 & 2.7 & 3.1 & 3.3 & 2.2 & 2.0 & 2.1 & 2.0 \\
\hline Std. Deviation & 1.6 & 1.3 & 1.4 & 1.4 & 1.6 & 1.5 & 1.5 & 1.6 & 1.5 & 1.1 & 1.0 & 1.1 & 1.1 \\
\hline
\end{tabular}

Table 9: Shows the Percentages of First 13 Items of Part Three (1-13)

As can be seen above, the previous table shows us percentages of answers for the first 13 questions of the questionnaire. To understand table (6), it is important to focus on the three colors, especially the orange color. The green color represented the lowest scores. The yellow color represented the highest scores. Meanwhile, the orange represented the right and correct answers and it showed to what extent EFL teachers need to pay attention concerning phonological awareness-raising training courses.

However, the highest score was for the favor of question number (13) to reach (48.5\%) for the choice (Blending). In other words, their answers were correct. Respectively, the question was 'What type of tasks would this be: "I am going to say some sounds that will make one word when you put them together? What does / sh/ / oe/ say?' This task is........'
(a) blending $\sqrt{(48.5 \%)}$
(b) rhyming
(c) segmentation
(d) substitution(10.5\%)'.
In contrast, (10.5) recorded the lowest score for the first question responding (segmentation) which was a wrong answer. However, the lowest score of the first (13) questions reached (2\%) for the favor of question (3) which was titled 'A pronounceable group of letters containing a vowel sound is a...... . Meanwhile, (32\%) responded to the choice (b). in other words, $32 \%$ responded in a wrong way. (a) phoneme $(15 \%) \quad$ (b) grapheme $(32 \%) \quad$ (c) syllable $\sqrt{(24 \%)} \quad$ (d) morpheme $(2 \%)^{\prime}$ Similarly, the highest mean was recorded among the first thirteen questions was (3.1) for the favor of question number (5) which was titled 'A combination of two or three consonants pronounced so that each letter keeps its own identity is called a... (a) silent consonant $\quad$ (b) consonant digraph(41\%) $\quad$ (c) diphthong $\quad$ (d) consonant blend (6\%) .

Comparatively, (41\%) responded wrongly to question number 5 through answering (b) and only (6\%) chose the appropriate answer. As a consequence, it necessarily reflects to what extent the lackness of teachers' knowledge about phonological awareness. Besides, both questions (8 and 9) also confirmed this reality. In both questions, the number of correct answers was (5.5\%) as opposed to the highest score for same items to record wrongly (35\%) for question 8 and also wrongly (38\%) for question 9 . Very few teachers could respond correctly to these two questions. Further, it can be noticed that all the percentages of the correct answers were less than $50 \%$ indicating low level of teachers' phonologically awareness. 


\begin{tabular}{|c|c|c|c|c|c|c|c|c|c|c|c|}
\hline & \multicolumn{2}{|c|}{ Item14/ttemi5 } & ftem16 & Item17 & Item18 & Hent & Stem20 & Item21 & Hen'2 & them23 & tem24 \\
\hline highest Score & $33 \% a$ & $37 \% a$ & $36.5 \% b$ & $61 \% a$ & $44.5 \% a$ & $37 \% c$ & $43.5 \% c$ & $43.5 \% \mathrm{~d}$ & $42 \% c$ & $41 \% b$ & $67 \% b$ \\
\hline the lowest score & $13 \% b$ & $15.0 \%$ & $15.5 \%$ & $9 \% c$ & $8.5 \% c$ & $10.0 \%$ & $8.5 \% a$ & $10 \% a$ & $11.5 \% \mathrm{~b}$ & $17.5 \% \mathrm{c}$ & $10 \% \mathrm{c}$ \\
\hline Number of rightanswers & $33 \% \mathrm{~A}$ & $21 \% B$ & $36 \% B$ & $61 \% \mathrm{~A}$ & $32.5 \% \mathrm{D}$ & $37 \% \mathrm{C}$ & $43.5 \% \mathrm{C}$ & $23.5 \% \mathrm{C}$ & $42 \% \mathrm{C}$ & $14 \% \mathrm{~A}$ & $67 \% B$ \\
\hline Mean & 2.7 & 2.2 & 2.5 & 1.8 & 2.3 & 2.4 & 2.6 & $3.5 \%$ & 2.5 & 2.6 & 2.2 \\
\hline Std. Deviation & 1.5 & 1.1 & 0.9 & 1.2 & 1.3 & 0.9 & 0.9 & 1.0 & 1.1 & 1.0 & 0.8 \\
\hline *Each cell contains a pe & tage a & the s) & of th & oice $p$ & & $\begin{array}{l}\text { Green } \\
\text { RIGT }\end{array}$ & $\begin{array}{l}\text { neans } \\
\text { INSWE }\end{array}$ & lowest & Yellow is & the hi & \\
\hline
\end{tabular}

Table 10: Shows the Percentages of Other Items of Part Three (14-24)

As can be seen above, the highest score was for the favor of question (24) to reach (67\%) for the choice (b). The question was about The word that we will get, if we read the word (bat) in reverse is.............." Of course the correct answer was (b). a) abt(10.5\%) b- tab $\sqrt{(67 \%)} \quad$ c- atb(10\%) d- bta $(12.5 \%)$.

Besides, question number (17) scored high percentage, too. The score reached (61\%) for choice (a) which came in rank two in the highest percentages. The questions were titled 'Count the number of syllables in the word (pics)......' . The right answer was (a). (a) $1 \sqrt{(61 \%) ~(b) ~ 2(12.5 \%) ~(c) ~ 3(9 \%) ~(d) ~} 4(17.5 \%)$

In contrast, two questions shared the same lowest percentage which was recorded (8.5\%). The questions were (18) and (20). Thus, for question (18), it was titled "If you say a word, and then reverse the order of the its sounds to be (ice) so the word would be....... The right answer was (d). (a) easy (44\%)

(d) $\operatorname{sigh} \sqrt{ }(61 \%)$

(b) sea(14.5\%)

(c) size (9\%)

Further, for question number (20), it was titled The rhyme of the word (knight) is ....... The correct answer was (c).

a)hit (8.5\%) b- knee(22\%) c- kite $\sqrt{(43.5 \%)}$ d- neat (26\%)

It was apparently clear that less than (50\%) responded properly to question (20) which reflect a kind of ignorance of phonological skills. Respectively, the highest score mean recorded was (3.5) for the favor of question number (21). The item was titled 'The onset and rime in the word (had) are as follow....'. The correct answer was (C). a- $(\mathrm{ad}, \mathrm{h})(10 \%) \quad$ b- $/ \mathrm{a} /(11.5 \%) \quad \mathrm{c}-(\mathrm{h}, \mathrm{ad}) \sqrt{(42 \%)} \quad \mathrm{d}-(\mathrm{h}, \mathrm{a}, \mathrm{d})(17.5 \%)$

In contrast, the lowest mean score reached (1.8) for the favor of item (17) which was titled 'Count the number of syllables in the word (pics)......' . Once again, the right answer was (a).
(a) $1 \sqrt{ }(61 \%)$
(b) $2(12.5 \%)$
(c) $3(9 \%)$
(d) $4(17.5 \%)$

\begin{tabular}{|c|c|c|c|}
\hline Mean & Variance & Std. Deviation & N of Items \\
\hline 61.3800 & 187.704 & 13.70052 & 24 \\
\hline
\end{tabular}

Table 11: Represents Scale Statistics of Part Three of the Questionnaire

\section{Conclusion and Recommendations}

The current paper has been conducted in order to investigate the EFL teachers' attitudes toward the employing and integrating phonological awareness explicitly in the English content taught in the EFL classrooms in Jordan. In addition, in order to examine the perspectives of EFL teachers to integrate phonological awareness tasks consciously in their daily lessons the tool of study, the questionnaire administered, was involved three parts to cover the teachers' thoughts and their beliefs. Respectively, the findings of the study were exciting and impressive. This study was consistent with Al shaboul study (2016). They confirmed the same findings: the dearth of teaching methods, the clear gap in phonological awareness and the shortcomings in PA. The results came fairly enough to confirm that there was a real problem among teachers of English concerning phonological awareness in both the sides, the theoretical side and the practical one. Theoretically, the majority of teachers detracted and reduced from the key role played by phonological awareness to enhance students' abilities to god readers and writers. As opposed, they even were uneducated about the PA levels and tasks to implement them in their classrooms.

The results of the study showed that most of the EFL teachers had the limit of knowledge about phonological awareness skills and even they ignored the key role of such awareness. It is obvious undoubtedly that most of the EFL teachers in Jordan were phonologically unaware. Most of their responses varied between having no idea and contradicting the guidelines of PA. Few percentages of responses were satisfactory and reflected little attention about the importance of developing students' sensitivity to the spoken structure of words, syllables and sentences. In general, teachers believed that this kind of awareness should have been developed in later stages of learning English as a foreign language. As a result, they had the limit of recognition about how to employ an important predictor such as phonological awareness in their daily lessons.

In the light of these findings, it is weighty to reflect on the courses taught at the Jordanian universities, professional training workshops given to whether pre-service or in-service English teachers in order to rehabilitate the majority of them. Besides, the rehabilitation programs should take into consideration longitudinal assessments during the 
EFL teachers' service. However, phonological awareness is considered as a predictor of literacy success and an index to fostering reading and writing skills. The stakeholders in the ministry of education should offer more awards and funded professional training courses for teachers of English in order to encourage them to attend these valuable workshops and courses and to create the desire to get benefit from the digital revolution and harness the potential as possible to help our students to be fluent readers and writers. And they should hold more awareness-raising courses about how improved teachers' phonological awareness practices in the future.

On the other hand, despite of what mentioned above, the image is not totally too dark. Some of the findings of the paper were positive. Findings revealed that a few teachers showed somehow some kind of professionalism and confirmed to what extent they were qualified and knowledgeable. For example, $31.5 \%$ confirmed that PA is a teachable skill that could be used at schools to teach students how to read. And this represented to what extent they were believed of its role and its applicability. Besides, according to the item that indicated the difference between letter name fluency and sound fluency, respondents were $21 \%$. Further, the item titled 'I know what rhyming is' revealed that $47 \%$ of respondents were knowledgeable. According to part three, $41 \%$ of respondents confirmed that the answer for the item titled the first item titled 'A phoneme refers to a ....... was (b).

(a) single letter (b) single speech sound (41\%) (c) single unit of meaning (d) grapheme.

The percentage of respondents recorded (48.5\%) for the item titled 'What type of tasks would this be: "I am going to say some sounds that will make one word when you put them together? What does / sh/ / oe/ say?"
(a) blending (48.5\%)
(b) rhyming
(c) segmentation
(d) substitution

\section{Recommendations}

The researcher recommended other researchers to shed light more on the teachers' capacities and their awareness to teach phonological awareness and its subtasks; segmentation, blending manipulation and other phonological types explicitly. He also encouraged the EFL teachers to integrate the phonological skills with the any curriculum employed in teaching English. Besides, the researcher recommended also EFL teachers to keep up to date revolutionary researches related to instruction methods.

\section{References}

i. Abu Nab'ah, A., Al Omari, H., Ihmeideh, F. and Wa'lly, S. (2009). Teacher Education Programs in Jordan: A Reform Plan. Journal of Early Childhood Teacher Education, 30:272-284. Routledge, Taylor and Francis Group. National Association of Early Childhood Teacher Educators.

ii. Al Bataineh, K. (2019). English Language Learning Beliefs of Jordanian Students: The Effect of Gender. Vol. 9, No. 2. International Journal of English Linguistics.

iii. Alhabahba, M. Pandian, A. and Mahfoodh, O. (2016). English language education in Jordan: Some recent trends and challenges. 3: 1156809 Cogent Education.

iv. Al Jamal, D. (2007). English Teaching and Learning Experiences in Jordan: Attitudes and View.Vol. 19- no.1. Umm Al-Qura University Journal of Educational \& Social Sciences \& Humanities.

v. AL-Jarrah, M., AL-Jarrah, M. And Talafhah, R, H. (2015). The Extent to which Jordan Opportunities 3 Meets the General Guidelines for English Language Teaching in Jordan. International Journal of Accounting and Financial Reporting. Vol. 5, No. 2. ISSN 2162-3082.

vi. Alkhawaldeh, A. (2017). School-based Teacher Training in Jordan: Towards On-school Sustainable Professional Development. Journal of Teacher Education for Sustainability, vol. 19, no. 2, pp. 51-68.

vii. Al Tamimi, Y and Rabab’ah, G. (2007). The relationship Between Phonological Awareness and Word Reading. Poznan Studies in Contemporary Linguistics. Vol .43, No.2

viii. Baddeley, A. and Gathercole.S.(2014). Working Memory and Language. Psychology Press.

ix. Baezzat, F, Moradi, M, Motaghedifard, M. (2018). The Effect of Phonological Awareness on the Auditory Memory in Students with Spelling Problems. Iranian Rehabilitation Journal. Volume 16, Number 1.

x. Cárnio, M., Vosgrau, J.and Soares, A. (2017). The role of phonological awareness in reading comprehension. Speech, language, hearing sciences and educational Journal. doi: 10.1590/19820216201719518316

xi. Cárnio, M., Vosgrau, Jand Soares, A. (2017). The role of phonological awareness in reading comprehension. Speech, language, hearing sciences and educational Journal. doi: 10.1590/19820216201719518316

xii. Gillon, G. (2017). Phonological Awareness, Second Edition: From Research to Practice. Second Edition. The Gulford Press.

xiii. Gillon.T.(2012). Phonological Awareness, Second Edition, From Research to Practice. The Gulford Press.

xiv. Goldsworthy, C and Pieretti, R. (2013). Sourcebook of Phonological Awareness Activities. Volume 4. CENGAGE Learning.

xv. Goswami, U and Bryant, P. (2016). Phonological Skills and Learning to Read. Essay in Developmental Psychology. Routledge, Taylor Francis Group.

xvi. Grawburg, M. and Rvachew, S. (2007). PA Intervention for Preschoolers with Speech Sound. Canadian Journal of Speech-Language Pathology and Audiology - Vol. 31, No.1

xvii. Kabadayi, A (2016). A Suggested In-service Training Model Based on Turkish Preschool Teachers Conceptions for Sustainable Development. Journal of Teacher Education for Sustainability. Volume 18: Issue 1, pp. 5-15 
xviii. McBride, C. (2015). Children's Literacy Development: A Cross-Cultural Perspective on Learning to Read and Write. Second Edition. Routledge, Taylor and Francis Group.

xix. SABER Country Report. (2015). System Approach for Better Education Results. World Bank Group.

xx. Schuele, C and Boudreau, D. (2008). Phonological Awareness Intervention: Beyond the Basics. LANGUAGE, SPEECH, AND HEARING SERVICES IN SCHOOLS. Vol. 39. 3-20. American Speech-Language-Hearing Association

xxi. Yassin, B. (2015). Challenges of Teaching English Language to English language learners at Private Universities in Jordan. Arab World English Journal. ISSN: 2229-9327.

xxii. Yopp, H and Yopp, R. (2010). Purposeful Play for Early Childhood Phonological Awareness. Shell Education.

\section{Appendix}

Dear Participant 1

I am Samer Hmeadat, a PhD student in uniSZA University, Malaysia. I am doing this research in order to investigate the EFL teachers' attitudes toward phonological awareness and their abilities to enrich their EFL classrooms with phonological awareness tasks. I am carrying out this survey titled The Attitudes of the Jordanian EFL Teachers' Toward Employing the Phonological Awareness in Teaching English.

You are kindly requested to take part in completing the attached questionnaire.

Please circle the appropriate response or fill in the blank as necessary.

Gender: Male Female

Total Years of Experience:

Education Level: BA MA

Certification: Primary Education () Elementary Education () Secondary Education ()

Number of Literacy Courses Taken:

Current Grade Level(s): K1+2 1st grade $\quad$ 2nd grade 3 rd grade

Other:

\begin{tabular}{|c|c|l|l|l|l|l|}
\hline No & Statements & Disagree & $\begin{array}{c}\text { Strongly } \\
\text { Disagree }\end{array}$ & $\begin{array}{c}\text { Agree } \\
\text { Strongly } \\
\text { Agree }\end{array}$ & $\begin{array}{c}\text { No } \\
\text { Idea }\end{array}$ \\
\hline 1 & $\begin{array}{c}\text { Phonological Awareness is a topic which I } \\
\text { studied at the university. }\end{array}$ & & & & & \\
\hline 2 & PA does not take care of the written language. & & & & & \\
\hline 4 & $\begin{array}{c}\text { The relationship between PA and reading is } \\
\text { weak. }\end{array}$ & & & & & \\
\hline 5 & $\begin{array}{c}\text { Poor PA (awareness of the individual sounds in } \\
\text { words) contributes to early reading failure. } \\
\text { PA is a teachable skill that can be used at } \\
\text { schools to teach students how to read. }\end{array}$ & & & & & \\
\hline 6 & $\begin{array}{c}\text { No difference between Letter Name Fluency and } \\
\text { Letter Sound Fluency. }\end{array}$ & & & & & \\
\hline 7 & $\begin{array}{c}\text { Teaching syllables is not important for the first } \\
\text { graders. }\end{array}$ & & & & & \\
\hline 8 & $\begin{array}{c}\text { Teaching the rime and onset is not important for } \\
\text { the first graders. }\end{array}$ & & & & & \\
\hline 9 & $\begin{array}{c}\text { Syllables, rimes and onsets should be taught in } \\
\text { the primary stage. }\end{array}$ & & & & & \\
\hline 10 & $\begin{array}{c}\text { Syllables, rimes and onsets should be taught in } \\
\text { the elementary and secondary stages. }\end{array}$ & & & & & \\
\hline 11 & $\begin{array}{r}\text { I spend more than 10 minutes in teaching } \\
\text { phonemic awareness. }\end{array}$ & & & & & \\
\hline
\end{tabular}

Table 12: Part One: Please Rate These Statements on the Following Scale 


\begin{tabular}{|c|c|c|c|c|}
\hline & Items & yes & No & No Idea \\
\hline 1 & I know well what Phonological Awareness is. & & & \\
\hline 2 & I know well all PA levels. & & & \\
\hline 3 & I know how to teach each level in the right way. & & & \\
\hline 4 & I know how to assess each level. & & & \\
\hline 5 & I know what rhyming is. & & & \\
\hline 6 & $\begin{array}{l}\text { I think that PA is a complicated issue that should not be } \\
\text { presented to first graders. }\end{array}$ & & & \\
\hline 7 & I think PA is a must for the first graders. & & & \\
\hline 8 & $\begin{array}{l}\text { I know quite well the importance of blending and } \\
\text { segmentation skills. }\end{array}$ & & & \\
\hline 9 & I appreciate the importance of PA manipulation skills. & & & \\
\hline
\end{tabular}

Table 13: Part Two: Tick the Appropriate Answer, Please

Part Three: Please circle the correct response.

1. Which word contains a short vowel sound?
(a) street
(b) start
(c) clip $\sqrt{ }$
(d) paw
(e) father

2. A phoneme refers to a:

(a) single letter (b) single speech sound $\sqrt{ }$ (c) single unit of meaning (d) grapheme.

3. A pronounceable group of letters containing a vowel sound is $a$ :
(a) phoneme
(b) grapheme
(c) syllable $\sqrt{ }$
(d) morpheme

4. If ( sine) were a word, the letter (i) would probably sound like the (i) in:
(a) if
(b) beautiful
(c) find $\sqrt{ }$
(d) ceiling
(e) sing

5. A combination of two or three consonants pronounced so that each letter keeps its own identity is called a:
(a) silent consonant (b) consonant digraph (c) diphthong
(d) consonant blend $\sqrt{ }$

6. A schwa sound is found in the word:
(a) bad
(b) phoneme $\sqrt{ }$
(c) stopping
(d) preview
(e) grouping

7. A diphthong is found in the word,
(a) coat
(b) boy $\sqrt{ }$
(c) battle
(d) sing
(e) been

8. A voiced consonant digraph exits in the word,
(a) think
(b) ship
(c) whip
(d) the $\sqrt{ }$
(e) photo

9. Two combined letters that represent one single speech sound are,
(a) schwa
(b) consonant blend
(c) phonetic
(d) digraph $\sqrt{ }(\mathrm{e})$ diphthong
10. How many speech sounds are there in the word eight?
(a) two
(b) three $\sqrt{ }$
(c) four
(d) five

11. Which one should be taught first?
(a) Lower case letters
(b) A-Z
(c) Consonants first
(d) Vowels first $\sqrt{ }$

12. What type of tasks would this be: "I am going to say a word and then I want you to break the word apart? Tell me each of the phonemes in the word "dog."
(a) blending
(b) rhyming
(c) segmentation $\sqrt{ }$
(d) isolation

13. What type of tasks would this be: "I am going to say some sounds that will make one word when you put them together? What does / sh/ / oe/ say?"
(a) blending $\sqrt{ }$ (b) rhyming
(c) segmentation
(d) substitution

14. A reading method that focuses on teaching the application of speech sounds to letters is called:
(a) phonics $\sqrt{ }$ (b) phonemics (c) orthography (d) phonetics
(e) either (a) or (d)

15. What is the rule for using a (ck) in spelling?
(a) when the vowel sound is a diphthong
(b) when the vowel sound is short $\sqrt{ }$
(c) when the vowel sound is long
(d) any of the above

16. Count the number of syllables in the word (unbelievable).
(a) 4
(b) $5 \sqrt{ }$
(c) 6
(d) 7

17. Count the number of syllables in the word (pics)
(a) $1 \sqrt{ }$
(b) 2
(c) 3
(d) 4

18. If you say a word, and then reverse the order of the its sounds to be (ice) so the word would be;
(a) easy
(b) sea
(c) size
(d) sigh $\sqrt{ }$

19- The rhyme of the word (took) is:
a- folk b- talk c- book $\sqrt{ }$
d- duke

20- The rhyme of the word (knight) is:

a- hit b-knee c-kite $\sqrt{ }$ d-neat

21- The onset and rime in the word(had) are as follow:

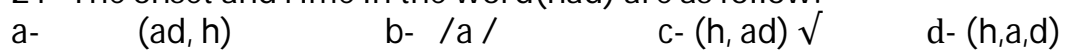

22-The onset and rime in the word (up) are as follow: 
a- $\quad(u, p) \quad$ b- $(u p, x) \quad c-(x, u p) \sqrt{ } \quad d-x, x=($ neither onset nor rime)

23- We teach the English alphabet to young learners according to,

a- Letter-sound relations $\sqrt{ } \quad$ b- letters only c-sounds only d-ABC Song

24- The word that we will get if we read the word (bat) in reverse is ... . a-abt b- tab $\sqrt{ } \quad$ c- atb d- bta. 